\title{
A Biometric System Based on Neural Networks and SVM Using Morphological Feature Extraction from Hand-Shape Images
}

\author{
Juan-Manuel RAMIREZ-CORTES ${ }^{1}$, Pilar GOMEZ-GIL ${ }^{2}$, \\ Vicente ALARCON-AQUINO ${ }^{3}$, David BAEZ-LOPEZ ${ }^{3}$, \\ Rogerio ENRIQUEZ-CALDERA ${ }^{1}$ \\ ${ }^{1}$ Electronics Department, National Institute of Astrophysics, Optics, and Electronics \\ Luis Enrique Erro No. 1, Tonantzintla, Puebla 72840, Mexico \\ ${ }^{2}$ Computer Science Department, National Institute of Astrophysics, Optics, and Electronics \\ Luis Enrique Erro No. 1, Tonantzintla, Puebla 72840, Mexico \\ ${ }^{3}$ Electrical and Computing Engineering Department, University of the Americas \\ Exhacienda Santa Catarina Martir, Cholula, Puebla 72820, Mexico \\ e-mail:jmram@inaoep.mx,pgomez@inaoep.mx,vicente.alarcon@udlap.mx, \\ david.baez@udlap.mx,rogerio@inaoep.mx
}

Received: June 2009; accepted: October 2010

\begin{abstract}
This paper presents a hand-shape biometric system based on a novel feature extraction methodology using the morphological pattern spectrum or pecstrum. Identification experiments were carried out using the obtained feature vectors as an input to some recognition systems using neural networks and support vector machine (SVM) techniques, obtaining in average an identification of $98.5 \%$. The verification case was analyzed through an Euclidean distance classifier, obtaining the acceptance rate (FAR) and false rejection rate (FRR) of the system for some $K$-fold cross validation experiments. In average, an Equal Error Rate of $2.85 \%$ was obtained. The invariance to rotation and position properties of the pecstrum allow the system to avoid a fixed hand position using pegs, as is the case in other reported systems. The results indicate that the pattern spectrum represents a good alternative of feature extraction for biometric applications.
\end{abstract}

Keywords: biometry, pattern spectrum, hand-shape, verification, identification.

\section{Introduction}

Biometric systems for automated personal identification and verification have received extensive attention in the last years. These systems aim to provide automatic recognition of an individual based on some physiological characteristics unique to each person. Biometric systems are based on various modalities such as fingerprints, iris, voice, face, ear shape, hand shape, palm prints, or dynamical features like gait, speech, on-line signature, and others (Jain, 2008; Kisel et al., 2008; Struc et al., 2009; Bastys et al., 2010). A biometric system can be operated in two modes: verification or identification. In verification mode, the system authenticates the person on the basis of his/her claimed identity. 


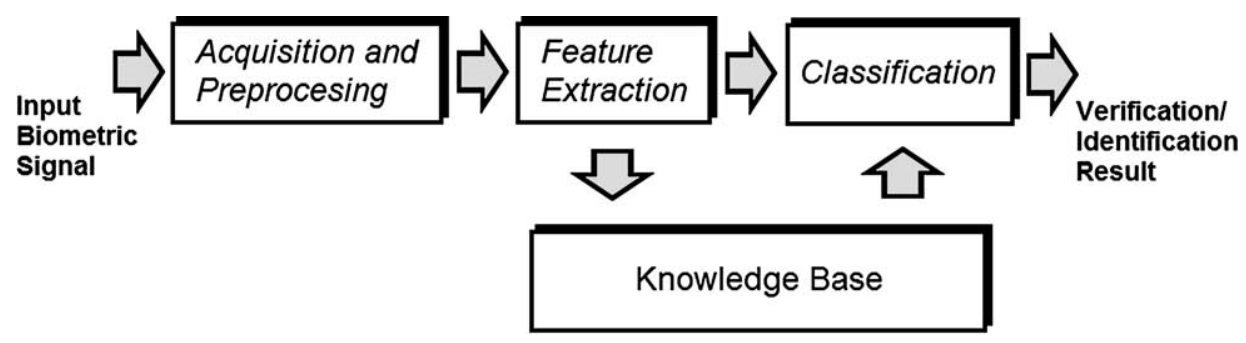

Fig. 1. General process of biometric verification/identification.

On the other hand, in identification mode, the system establishes the person's identity among those enrolled in a database, without the subjects having to claim their identity. Figure 1 sketches the three main phases of a general biometric system: data acquisition and preprocessing, feature extraction, and classification.

Strength and weakness of each modality, according to the required biometric application, have been widely reported in the literature. Among these modalities, hand shape recognition has received significant attention due in part to its convenience in setup complexity, and its psychological acceptance as a non invasive method, since it does not produce anxiety in the user like other techniques. Hand-based biometric systems, however, are usually employed in small to medium scale person verification applications due to the fact that geometric features of the hand are not as distinctive as fingerprint or iris features (Yoruk et al., 2006; Amayeh et al., 2006). In the last years some commercial systems have been developed, and new algorithms are being proposed. Many hand-based biometric techniques use geometric features such as finger and palm heights, finger geometry (Su, 2007), aspect ratio of the palm to fingers (Su, 2008; Fouquier et al., 2007; Bulatov et al., 2004), palm print information, palm contour or a combination of palm print features and geometric measurements (Kumar et al., 2006; Yoruk et al., 2006), as well as bimodal approaches, such as combination of palmprints and faces (Ribari et al., 2008). Several mathematical approaches for feature extraction have been proposed, such as Hausdorff distance (Yoruk et al., 2006), B-spline curves (Liang et al., 2004), geometric implicit polynomials (Oden et al., 2003), or high order Zernike moments (Amayeh et al., 2006). In this paper, we use the morphological operator pecstrum, previously reported from our research group as a novel feature extractor for a shape-based hand recognition system (Ramirez-Cortes et al., 2009). We extend the previous work by incorporating the feature extraction methodology into some classifiers, which conforms a whole biometric system. For that purpose, a neural network with a structure of a feedforward multilayer perceptron, a support vector machine (SVM) classifier, and a distance-based classifiers, were selected for comparison purposes. The system operates on two dimensional binary hand silhouette images, obtained by placing the hand on a commercial flatbed scanner, inside of a predefined square. The properties of invariance to rotation and position of the pattern spectrum, provide flexibility to the system by allowing the user to pose naturally the hand without additional constraints. This is an advantage over some reported systems, where a fixed hand position using pegs is required. The only setup additional 
to the flatbed scanner was the use of additional lighting located at the frontal side and under the arm of the subject. This setup allowed the scanner to get rid of the wrist, which does not provide additional information in relevance to the recognition process. The rest of the paper is organized as follows. In Section 2, we briefly describe background concepts on the morphological pattern spectrum, as well as a short review on some reported applications. Section 3 presents the model of our feature extraction scheme based on the pattern spectrum from the images in the database, as well as a statistical analysis of the obtained data. In Section 4, we describe the selected classification methods using neural networks and SVM. Finally, results and concluding remark are presented in Sections 5 and 6, respectively.

\section{The Morphological Pattern Spectrum as a Feature Extractor}

Morphological image processing is a nonlinear theory and technique to quantitatively describe operations effective for the shape of objects in an image (Ledda et al., 2005; Lefebre, 2009). The morphological operators are described by combinations of a basic set of numerical manipulations between an image A and a small object B, called a structuring element, which can be seen as a probe that scans the image and modifies it according to some specified rule. The shape and size of B, typically much smaller than the image A, together with the specific rule, define the characteristics of the performed process. An interesting morphological operator is the pattern spectrum or pecstrum. This operator decomposes the target image in morphological components according to the shape and size of the structuring element, providing a quantitative analysis of the morphological content of the image (Ledda et al., 2005).

Pecstrum was originally developed and reported by Maragos (1989), and Pitas (1990). Although it presents excellent properties as a shape extractor, with invariance to translation and rotation, pecstrum has not been extensively used, probably because it results computationally intensive in some applications, however, the available current hardware solutions easily overcome this disadvantage. The pattern spectrum has been used in the last years with several purposes: Analysis of partial discharges in high voltage systems (Yun-Peng et al., 2005), texture analysis in several applications, such as images of debris particles in polymers and composite materials (Ghosh, 2006; Ledda et al., 2004), lip recognition (Omata et al., 2001), and cytology of bone marrow images for the counting of white blood cells based on morphological granulometries (Theera-Umphon and Dhompongsa, 2007). In this work, we use the pattern spectrum as a novel feature extractor for obtaining quantitative information regarding the hand shape, as the input for a biometric system. To the best of our knowledge, pattern spectrum has not been used previously as a feature extractor in hand-shape biometrics applications.

Binary-image mathematical morphology is based on two fundamental operators extensively presented in the literature as dilation, and erosion. Theoretical background on these operations can be found elsewhere; see for instance (Lefebre, 2009). The backbone of the pattern spectrum is the opening morphological filter, which is defined as an 
operation formed by the serial application of an erosion and a dilation using the same structuring element. The opening filter is expressed as:

$$
A \circ B=(A \Theta B) \oplus B,
$$

where $A$ represents a binary image, and $B$ is the structuring element. In the opening operator the dilation tries to undo the erosion operation, however, some details closely related to the shape and size of the structuring element will vanish. Furthermore, an object disappearing as consequence of the erosion can not be recovered. In a pattern spectrum the progressive vanishing of the image is numerically captured by measuring the differences in area in each step. Formally, the pattern spectrum of a compact binary image $A \subseteq R^{2}$, relative to a convex binary pattern $B \subseteq R^{2}$, is defined as the differential size distribution function:

$$
P_{x}(n, B)=\frac{d M(A \circ n B)}{d n}, \quad n \geqslant 0,
$$

where $M$ represents the area measured in the intermediate operations, and $n B$ is the $n$-times dilated structuring element. The discrete form of the pattern spectrum is given by:

$$
P(n, B)=\frac{M[A \circ n B]-M[A \circ(n+1) B]}{M[A]} .
$$

The pecstrum has the property of invariance to translation and rotation when $B$ is an isotropic structuring element. Scale is determined by the size of the structuring element.

\section{Experimental Setup: Acquisition, Preprocessing, and Feature Extraction}

The images were acquired from the right hand of the subjects using a flatbed scanner in an unconstrained pose at $50 \mathrm{dpi}$, and reduced to a size of $256 \times 256$ pixels. The subjects were asked to stretch naturally their hand, and place it inside a square drawn on the scanner without additional restrictions. A setup with lateral underlight illumination located under the arm of the subject, was used in order to automatically get rid of the area corresponding to the wrist. The images obtained are shown in Fig. 2. In previous works the hand segmentation has been accomplished through several approaches: In Amayeh et al. (2006) the palm is detected by finding the largest circle inscribed in the hand arm silhouette using morphological operators. Then, the intersection of the forearm with the boundary of the circle is used to limit the form of the palm-shape. Fouquier et al. (2008) performed the hand-shape segmentation by drawing a wrist line based on geometrical considerations and ad hoc criteria related to the measurement of the largest palm width. In Yoruk et al. (2006) two approaches to synthesize a wrist boundary were used. The first approach was a curve completion algorithm called the Euler spiral, which furnishes a natural completion of the hand-shape contour in the wrist part. Their second approach was 


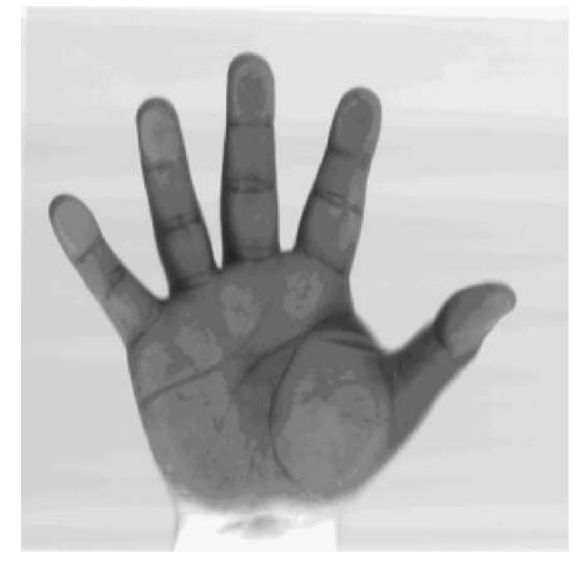

(a)

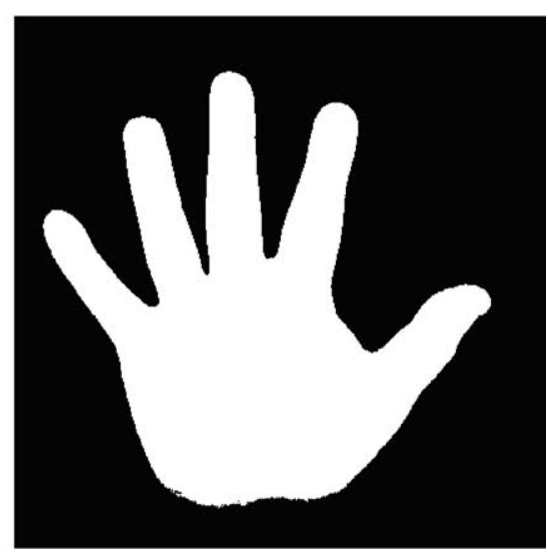

(b)

Fig. 2. Feature extraction. (a) Gray scale captured image. (b) Binary segmented image.

just a guillotine cut of the hand-shape at the same latitudes determined by some specific points. In this work we used a setup with lateral underlight illumination, which provided a simple and automatic segmentation. Once the image was acquired, The palm shape was segmented by simple binarization and contrast inversion, with a gray level thresholding method using an experimentally determined threshold of 150 , without additional processing. Figure 3 shows the pecstrum-based feature vectors obtained from four hand-shape images corresponding to the same subject, while Fig. 4 shows the feature vectors obtained from four different subjects. As can be seen, although the basic structure of the pecstrumbased feature vectors is the same in both cases, there are differences in the values of $P(n)$ which allow the system to distinguish between different subjects. The maximum vector length obtained was $n=25$, which corresponds to the last iteration in which the image vanishes. In a typically obtained hand-shape pattern spectrum, the central values reflected the morphological constitution of the fingers, while the last values provided information regarding the central palm shape. The execution time of erosion and dilation increases exponentially with the size of the structuring element. Furthermore, it was found that no additional information about the hand-shape was obtained in the last stages, due to the tendency of the central part of the hand to approximate a round form. Computation of the pecstrum was optimized by doubling the step size of the structuring element in the last stages when half the area of the hand shape is surpassed.

A group of 400 images of the right hand, 10 samples from each subject, for 40 subjects, was collected. In order to get information about the vector data spreading in an $n$-dimensional space, a basic statistic analysis was performed using the Euclidean distance. The results obtained are shown in Table 1. Figure 5 shows as an example, the Euclidean distances obtained from the first sample to the rest of the samples in the constructed database.

The samples within each group included hand-shapes images with natural finger vari- 


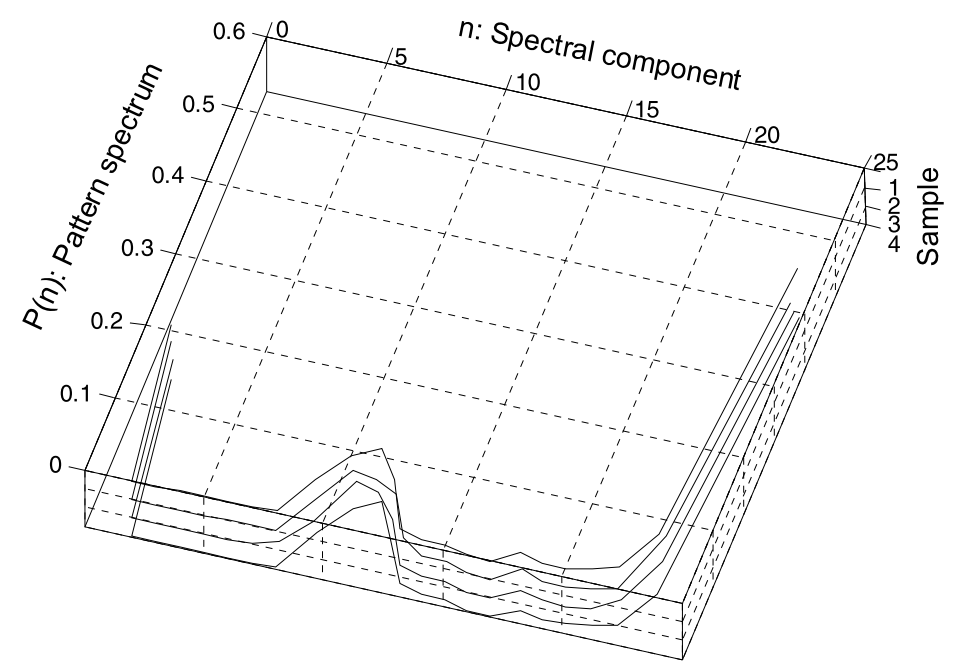

Fig. 3. Pattern spectrum feature vectors corresponding to four samples from the same subject.



Fig. 4. Pattern spectrum feature vectors corresponding to four samples from different subjects.

Table 1

Statistical information on the collected data

\begin{tabular}{ll}
\hline Maximum Euclidean distance between samples & 0.79890 \\
Average distance between mean classes & 0.46966 \\
Average mean distance within samples in each group & 0.04456 \\
Average standard deviation within samples in each group & 0.01232
\end{tabular}




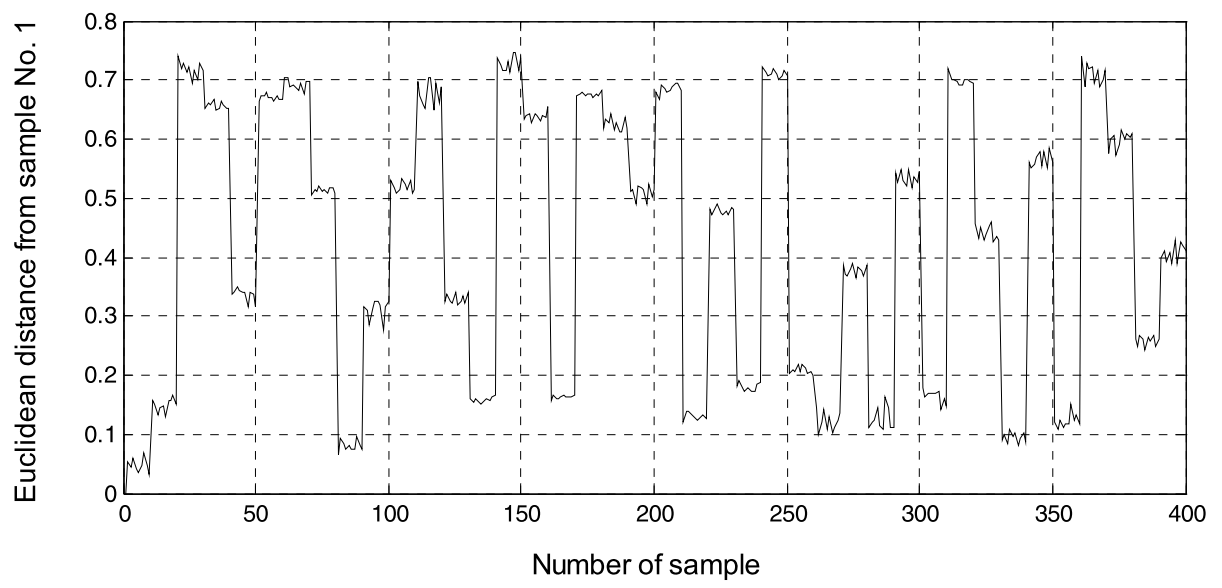

Fig. 5. Euclidean distance from the first sample to the rest of the feature vectors in the database.

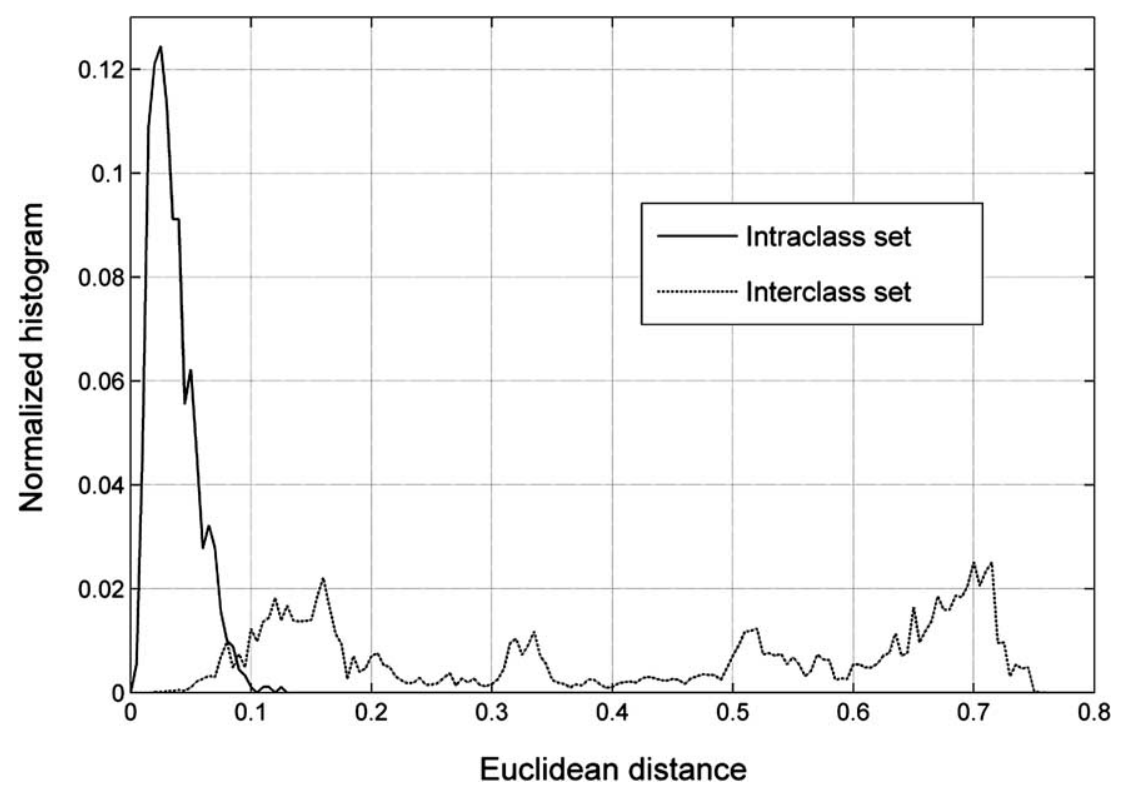

Fig. 6. Distribution of inter and intra-class Euclidean distances.

ations in the position between samples. According to the obtained results, the pattern spectrum is able to tolerate finger displacements, and to extract a good representation of the morphological constitution of the hand shape. Figure 6 shows the normalized histograms of the Euclidean distances for intra and interclass sets in the constructed database. 


\section{Classification}

The novel described feature extraction method based on the pattern spectrum was used to implement the first two blocks described in Fig. 1. The classification stage was implemented using an Euclidean distance classifier, and two selected soft-computing approaches: A multilayer perceptron neural network, and a Support Vector Machine (SVM) algorithm. These techniques are briefly described as follows:

\subsection{Neural Network}

A feed forward single-layer perceptron trained with the Levenberg-Marquardt back propagation algorithm (Demuth, 2001), was used in this work. The backpropagation algorithm used in the training of multilayer perceptrons, is formulated as a non linear least-squares problem. Essentially, the Levenberg-Marquardt algorithm is a least-squares estimation method based on the maximum neighborhood idea. Let $E(w)$ be an objective error function made up of $m$ individual error terms $e_{i}^{2}(w)$ as follows:

$$
E(w)=\sum_{i=1}^{m} e_{i}^{2}(w)=\|f(w)\|^{2}
$$

where

$$
e_{i}^{2}(w)=\left(y_{d i}-y_{i}\right)^{2}
$$

$y_{d i}$ is the desired value of output neuron $i$, and $y_{i}$ is the actual output of that neuron. It is assumed that function $f(\cdot)$ and its Jacobian $J$ are known at point $w$. The aim of the Levenberg-Marquardt algorithm is to compute the weight vector $w$ such that $E(w)$ is minimal. In each iteration the weight vector is updated according to (6):

$$
w_{k+1}=w_{k}+\delta w_{k}
$$

where

$$
\delta w_{k}=-\left(J_{k}^{T} f\left(w_{k}\right)\right)\left(J_{k}^{T} J_{k}+\lambda I\right)^{-1} .
$$

$J_{k}$ is the Jacobian of $f$ evaluated at $w_{k}, \lambda$ is the Marquardt parameter, and $I$ is the identity matrix.

\subsection{Support Vector Machines (SVM)}

Briefly, SVM is described as a statistical learning method based on a structural risk minimization procedure (Cristianini et al., 2002). The basic concept of the algorithm is a mapping of the input space into a higher dimensional feature space. Mapping can be done either linearly or non-linearly, according to the used kernel function. In the new 
feature space, the SVM constructs separating hyperplanes that are optimal in the sense that the classes are separated with the largest margin and minimum classification error. The optimal hyperplane can be written as a combination of a few feature points, which are called the support vectors of the optimal hyper plane. Classification of the test sample $x$ is performed by:

$$
y=\operatorname{sgn}\left(\sum_{i=1}^{N} \alpha_{i} y_{i} K\left(s_{i}, x\right)\right),
$$

where $N$ is the number of training samples, $y_{i}$ is the class label, $\alpha_{i}$ is the Lagrangian multiplier, the elements $x_{i}$ for which $\alpha_{i}>0$ are the support vectors, and $K\left(s_{i}, x\right)$ is the function kernel. In this work a Gaussian radial basis was used.

\subsection{Minimum Euclidean Distance Classifier}

The Euclidean distance is a well known metric extensively used in several classification methodologies. The Euclidean distance between two $n$-dimensional vectors $x, y$ is defined as:

$$
d_{x, y}=\sqrt{\sum_{i=1}^{n}\left(x_{i}-y_{i}\right)^{2}}
$$

where $x$ is the sample feature vector, and $y$ is the template feature vector. The object under test is assigned to the nearest prototype among the $N$ classes, using the minimumEuclidean-distance criteria, where each prototype is obtained as the mean vector of the $M$ samples in each class. In this work $N=40, M=10$.

\section{Results}

In a biometric system, performance is usually evaluated in two cases: verification and identification. In the 'verification' case the system is expected to check the user claimed identity providing a binary answer in the form of 'accepted' or 'rejected'. In the 'identification' case the system is expected to identify who the user is, from a collection of classes stored in a database.

\subsection{Experiments on 'Verification'}

The described feature extraction methodology was tested for the 'verification' case with the 400 samples database using an Euclidean distance-based classification algorithm. A two-fold cross validation was carried out by dividing the database in two groups, with 5 samples per subject en each group. The first group was used as enrollment template, while the second group was used for the authentication process. The experiment was 
repeated 10 times, selecting randomly in each case the enrollment template. The performance was evaluated through the False Acceptance Rate (FAR) and False Rejection Rate (FRR), defined as follows:

$$
\begin{aligned}
& \text { FRR }=\frac{\text { Number of false rejections }}{\text { Number of accesses }}, \\
& \text { FAR }=\frac{\text { Number of false acceptances }}{\text { Number of accesses }} .
\end{aligned}
$$

In a biometric system, FRR and FAR show a behavior with a tradeoff, allowing the designer to adjust the system according to the situation through the displacement of a threshold (DTH). The threshold represents the Euclidean distance which gives the separation point between matching and non-matching accesses. The Equal Error Rate (EER) is defined as the point in which FRR and FAR exhibit the same value. Table 2 shows the obtained average FAR and FRR results for different DTH values for the total population in the database. The system performance is usually expressed through a Receiver Operation Characteristic plot (ROC), which represents the operating points of the system. Figure 7 shows the average ROC curve obtained in this experiment. An Equal Error Rate (EER) of 0.0285 was obtained at a decision threshold of DTH $=0.0675$.

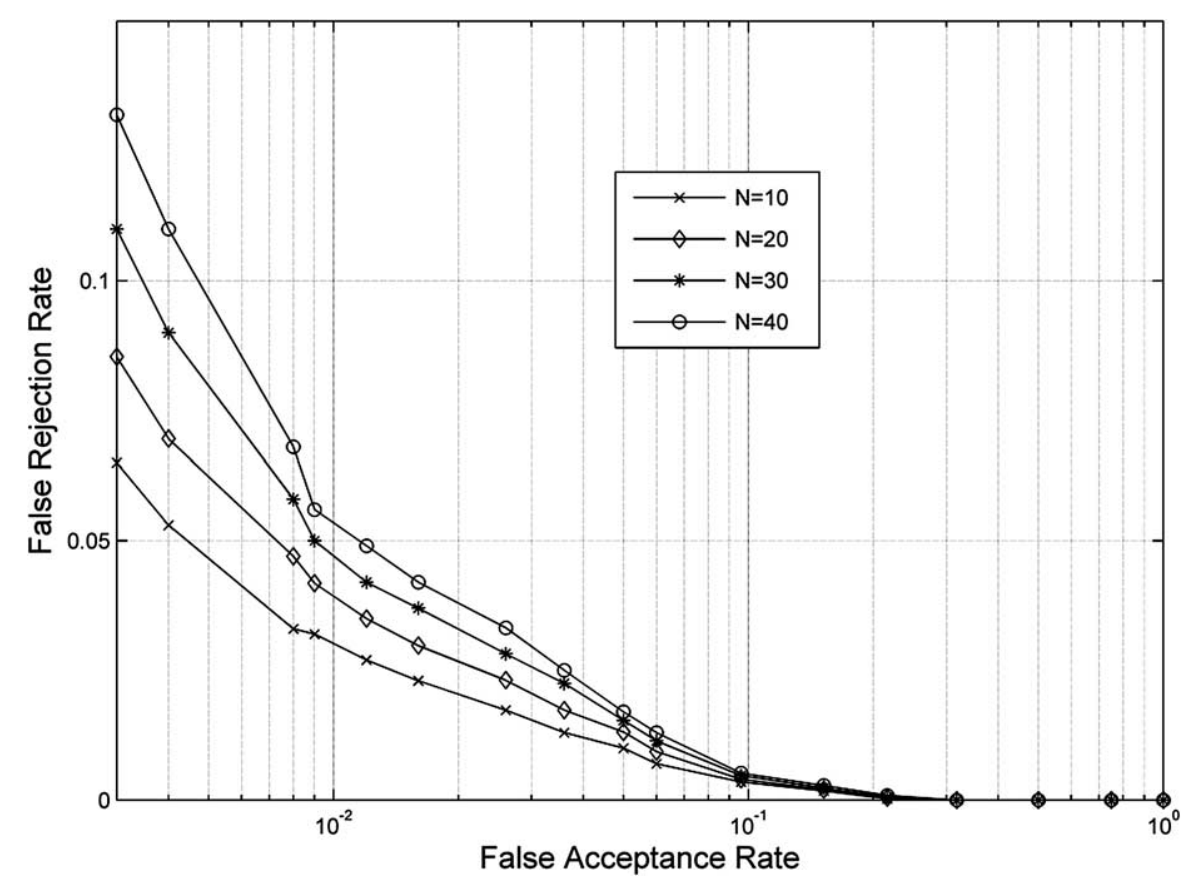

Fig. 7. Average Receiver Operation Characteristic curve (ROC). 
Table 2

Average FRR and FAR in percentage values

\begin{tabular}{lrl}
\hline $\begin{array}{l}\text { Euclidean distance } \\
\text { threshold DTH }\end{array}$ & FRR & FAR \\
\hline 0.035 & $29.20 \%$ & 0 \\
0.045 & $15.00 \%$ & $0.27 \%$ \\
0.060 & $3.90 \%$ & $1.29 \%$ \\
0.0675 & $2.85 \%$ & $2.85 \%$ \\
0.075 & $1.20 \%$ & $3.86 \%$ \\
0.095 & $0.20 \%$ & $10.2 \%$ \\
0.105 & 0 & $14.5 \%$ \\
\hline
\end{tabular}

\subsection{Experiments on 'Identification'}

For the identification experiments the following supervised classifiers were tested.

The network architecture used in this work was composed of 25 input nodes, a hidden layer of 25 nodes, and 20 output nodes. All neurons used a sigmoid as an activation function. Convergence of the Levenberg-Marquardt algorithm is very fast. Figure 8 shows an example of a typical training session with the hand-shape database constructed using the described feature extraction. In this example the network was trained after 20 epochs.

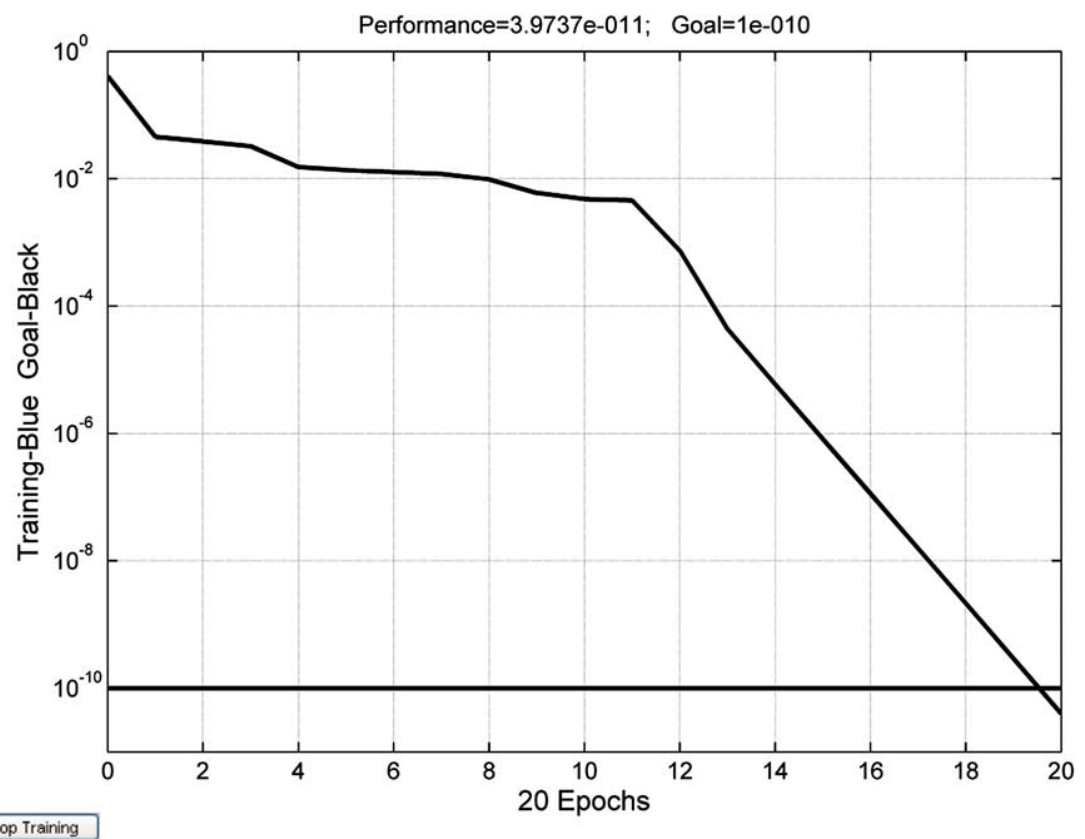

Fig. 8. An example on NN training performance. 
Table 3

Comparison of verification and identification performance in this work with several reported methods

\begin{tabular}{|c|c|c|c|c|c|c|}
\hline Reference & Number & Number & Features & Classification & Performance & \\
\hline & $\begin{array}{l}\text { of } \\
\text { subjects }\end{array}$ & $\begin{array}{l}\text { of samples } \\
\text { per subject }\end{array}$ & & approach & Verification & $\overline{\text { Identification }}$ \\
\hline $\begin{array}{l}\text { Wong et al. } \\
(2002)\end{array}$ & 22 & 12 & $\begin{array}{l}\text { Geometric } \\
\text { features and } \\
\text { fingertip regions }\end{array}$ & $\begin{array}{l}\text { Gaussian } \\
\text { mixtures } \\
\text { models (GMM) }\end{array}$ & $\begin{array}{l}\mathrm{FAR}=0.022 \\
\mathrm{FRR}=0.1111\end{array}$ & $96 \%$ \\
\hline $\begin{array}{l}\text { Ribaric } \\
\text { et al. }(2003)\end{array}$ & 130 & 5 & $\begin{array}{l}\text { Geometric } \\
\text { features }\end{array}$ & $\begin{array}{l}\text { Euclidean } \\
\text { distance }\end{array}$ & $\begin{array}{l}\mathrm{FAR}=0.153 \\
\mathrm{FRR}=0.13\end{array}$ & - \\
\hline $\begin{array}{l}\text { Oden } \text { et al. } \\
\text { (2003) }\end{array}$ & & & $\begin{array}{l}\text { Geometric } \\
\text { features } \\
\text { and implicit } \\
\text { polynomials }\end{array}$ & $\begin{array}{l}\text { Mahalanobis } \\
\text { distance }\end{array}$ & $\mathrm{FAR}=0.01$ & $\begin{array}{l}98 \% \text { with } \\
\text { PCA 99\% } \\
\text { whole fea- } \\
\text { ture vector }\end{array}$ \\
\hline $\begin{array}{l}\text { Liang et al. } \\
(2004)\end{array}$ & 20 & 6 & $\begin{array}{l}B \text {-spline curves, } \\
\text { thumb-length and } \\
\text { palm-width }\end{array}$ & $\begin{array}{l}\text { Minimum distance } \\
\text { between a point } \\
\text { and a } B \text {-spline } \\
\text { curve }\end{array}$ & $\mathrm{EER}=0.05$ & $97 \%$ \\
\hline $\begin{array}{l}\text { Bulatov } \\
\text { et al. (2004) }\end{array}$ & 70 & 10 & $\begin{array}{l}30 \text { geometric } \\
\text { features }\end{array}$ & $\begin{array}{l}\text { Nearest box and } \\
\text { Euclidean ball }\end{array}$ & $\begin{array}{l}\mathrm{FAR}=0.01 \\
\mathrm{FRR}=0.03\end{array}$ & $94 \%$ \\
\hline $\begin{array}{l}\text { Xiong et al. } \\
(2005)\end{array}$ & 108 & 5 & $\begin{array}{l}\text { Geometric } \\
\text { features. Width of } \\
\text { fingers at several } \\
\text { points }\end{array}$ & $\begin{array}{l}\text { Distance between } \\
\text { width feature } \\
\text { vectors }\end{array}$ & $\begin{array}{l}\text { EER up to } \\
0.0241\end{array}$ & $97.48 \%$ \\
\hline $\begin{array}{l}\text { Amayeh } \\
\text { et al. }(2006)\end{array}$ & 40 & 10 & Zernike moments & $\begin{array}{l}\text { Euclidean } \\
\text { distance }\end{array}$ & $\begin{array}{l}\mathrm{FAR}=0.01 \\
\mathrm{FRR}=0.0242 \\
\mathrm{EER}=0.0164\end{array}$ & - \\
\hline $\begin{array}{l}\text { Kumar et al. } \\
(2006)\end{array}$ & 100 & 10 & $\begin{array}{l}\text { Geometric } \\
\text { features and } \\
\text { hand area }\end{array}$ & $\begin{array}{l}\text { Normalized } \\
\text { correlation }\end{array}$ & $\begin{array}{l}\text { FRR }=0.0834 \\
\text { when } \\
\text { FAR }=0.01\end{array}$ & - \\
\hline $\begin{array}{l}\text { Fouquier } \\
\text { et al. }(2007)\end{array}$ & 750 & $3 / 6$ & $\begin{array}{l}\text { Finger geometry } \\
\text { measurements }\end{array}$ & $\begin{array}{l}\text { Symmetric } \\
\text { Kullback-Leibler } \\
\text { distance }\end{array}$ & $\mathrm{EER}=0.0421$ & $\begin{array}{l}88.92 \% \\
\text { with } 750 \\
93.54 \% \\
\text { with } 100\end{array}$ \\
\hline \multirow[t]{2}{*}{ This work } & 40 & 10 & $\begin{array}{l}\text { Morphological } \\
\text { pattern spectrum }\end{array}$ & $\begin{array}{l}\text { Euclidean } \\
\text { distance }\end{array}$ & $\begin{array}{l}\mathrm{FRR}=0.052 \\
\text { when } \\
\mathrm{FAR}=0.01 \\
\mathrm{EER}=0.0285\end{array}$ & - \\
\hline & & & & $\begin{array}{l}\text { Neural Network } \\
\text { (NN), Support } \\
\text { Vector Machine } \\
\text { (SVM) }\end{array}$ & - & $\begin{array}{l}\text { NN: } \\
98.5 \% \\
\text { SVM: } \\
99 \%\end{array}$ \\
\hline
\end{tabular}


A two-fold cross validation scheme was followed in the three recognition methods, using half of the samples for training and the other half of the samples for generalization. The experiments were repeated ten times, selecting both groups randomly in each case. Table 3 shows the average verification and identification rates obtained with the recognition systems previously described. These results are very competitive when they are compared with systems reported in the literature, although a direct comparison is not possible due to the differences in database size, number of samples, and image acquisition.

\section{Conclusions}

A hand-shape biometric system using some soft computing techniques, such as neural networks and support vector machines, and a novel feature extraction based on the morphological pattern spectrum has been presented. A comparison with results obtained from different feature extraction methods reported in the literature shows a very competitive performance. The properties of invariance to rotation and position of the pattern spectrum allow the user to pose naturally the hand without additional constraints, in contrast to other reported methods which might require a peg-based fixed position of the hand. The results obtained in average are an EER $=0.0285$ for verification, $98.5 \%$ for identification using a multilayer perceptron, and 99\% with a SVM algorithm used in identification mode, as well. The Levenberg-Marquardt back propagation algorithm provided an accurate and fast training process, reaching the trained point after 24 epochs in average. The best identification rate was obtained through the SVM algorithm. The obtained results indicate in general that the pattern spectrum represents a good choice of feature extraction methodology for low and medium scale applications. Furthermore, the method could be enhanced by incorporating additional information, such as palm print features in a data integration manner. An FPGA implementation of the system is currently in construction in our research group, aiming to the implementation of a prototype for real-time applications.

\section{References}

Amayeh, G., Bebis, G., Erol, A., Nicolescu, M. (2006). Peg-free hand shape verification using high order Zernike moments. In: Proc. IEEE Conference on Computer Vision and Pattern Recognition Workshop. New York, USA, pp. 40-48.

Bastys, A., Kisel, A., Salna, B. (2010). The use of group delay features of linear prediction model for speaker recognition. Informatica, 21(1), 1-12.

Bulatov, Y., Jambawalikar, S., Kumar, P., Sethia, S. (2004). Hand recognition using geometric classifiers. In: Proc. International Conference on Biometric Authentication, Vol. 3072, Hong Kong, Chine, pp. 753-760.

Cristianini, N., Scholkopf, B. (2002). Support vector machines and kernel methods. The new generation of learning machines. AI Magazine, 23(3), 31-41.

Demuth, H., Beale, M. (2001). Neural Network Toolbox for Use with MATLAB. The MathWorks.

Dutagaci, H., Sankur, B., Yoruk, E. (2008). Comparative analysis of global hand appearance-based person recognition. Journal of Electronic Imaging, 17(1), 1801-1819. 
Fouquier, G., Likforman, L., Darbon, J., Sankur, B. (2007). The biosecure geometry-based system for hand modality. In: Proc. IEEE ICASSP, Honolulu, Hawai, USA, pp. I801-I804.

Ghosh, D., Tou Wei, D.C. (2006). Material classification using morphological pattern spectrum for extracting textural features from material micrographs. In: Proc. Asian Conference on Computer Vision, Hyderabad, India. LNCS, Vol. 3852, pp. 623-632.

Jain, A.K. (2008). Handbook of Biometrics, Springer, Berlin.

Kisel, A., Kochetkov, A., Kranauskas, J. (2008). Fingerprint minutiae matching without global alignment using local structures. Informatica, 19(1), 31-44.

Kumar, D.C.M., Shen, H.C., Jain, A.K. (2006). Personal authentication using hand images. Pattern Recognition Letters, 27, 1478-1486.

Ledda, A., Phillips, W. (2005). Majority ordering and the mMorphological pattern spectrum. In: Proc. Advanced Concepts for Intelligent Vision Systems, Antwerpen, Belgium, pp. 356-363.

Ledda, A., Samyn, P., Quintelier, J., Baets, P.D., Phillips, W. (2004). Polymer analysis with mathematical morphology. In: Proc. IEEE Benelux Signal Processing Symposium, Hilvarenbeek, The Netherlands, pp. 87-92.

Lefebre, S. (2009). Beyond morphological size distribution. Journal of Electronic Imaging, 18(1), 1-10.

Liang, Y., Pollik, M.F., Hewitt, W.T. (2004). Using B-spline curves for hand recognition. In: Proc. IEEE International Conference on Pattern Recognition, Cambridge, UK, pp. 274-277.

Maragos, P. (1989). Pattern spectrum and multiscale shape representation. In: IEEE Transactions on Pattern Analysis and Machine Intelligence, Vol. 11. pp. 701-716.

Mitome, A., Ishii, R. (2003). A comparison of hand shape recognition algorithms. In: Proc. IEEE Annual Conf. of the Ind. Elec. Soc., Roanoke, Virginia, USA, pp. 2261-2265.

Oden, C., Ercil, A., Buke, B. (2003). Combining implicit polynomials and geometric features for hand recognition. Pattern Recognition Letters, 24, 2145-2152.

Omata, M., Hamamoto, T., Sangai, S. (2001). Lip recognition using morphological pattern spectrum. In: Proc. of the Third International Conference on Audio and Video-Based Biometric Person Authentication, Halmstad, Sweeden, pp. 108-114.

Pitas, A., Venetsanopoulus, A.N. (1990). Non-linear Digital Filters; Principles and Applications, Kluwer Academic, Dordrecht.

Ramirez-Cortes. J.M., Gomez-Gil, P., Sanchez-Perez, G., Prieto-Castro, C. (2009). Shape-based hand recognition approach using the pattern spectrum. Journal of Electronic Imaging, 18(1), 1-6.

Ribari, S., Fratri, I., Kis, K. (2008). A novel biometric personal verification system based on the combination of palmprints and faces. Informatica, 19(1), 81-100.

Ribaric, S., Ribaric, D., Pavesic, N. (2003). Multimodal biometric user-identification system for network-based applications. IEE Proceedings on Vision, Image, and Signal Processing, 50(6), 409-416.

Scholkopf, B., Smola, A.J. (2002). In: Learning with Kernels: Support Vector Machines, Regularization, Optimization, and Beyond. MIT Press, Cambridge, pp. 189-211.

Struc, V., Pavesi, N. (2009). Gabor-based kernel partial-least squares discrimination features for face recognition. Informatica, 20(1), 115-138.

Su, C.L. (2007). Overlapped finger geometry signal processing and finger shape comparisons for person identification. Informatica, 18(3), 447-456.

$\mathrm{Su}$, C.L. (2008). Hand image recognition by the techniques of hand shape scaling and image weight scaling. Expert Systems with Applications, 34, 2976-2987.

Theera-Umphon, N., Dhompongsa, S. (2007). Morphological granulometric features of nucleus in automatic bone marrow white blood cell classification. IEEE Transactions on Information Technology in Biomedicine, 11(3), 353-359.

Wong, A.L.N., Shi, P. (2002). Peg free hand geometry recognition using hierarchical geometry and shape matching. In: IAPR Workshop on Machine Vision Applications, Japan, pp. 281-284.

Xiong, W., Toh, K., Yau, W., Jiang, X. (2005). Model-guided deformable hand shape recognition without positioning aids. Pattern Recognition, 38, 1651-1664.

Yoruk, E., Konukoglu, E., Sankur, B., Darbon, J. (2006). Shape-based hand recognition. IEEE Transactions on Image Processing, 15(7), 1803-1815.

Yoruk, E., Dutagaci, H., Sankur, B. (2006). Hand biometrics. Image and Vision Computing, 24, 483-497.

Yun-Peng, L., Fang-Cheng, L., Cheng-Rong, L. (2005). Pattern recognition of partial discharge based on its pattern spectrum. In: Proc. Internacional Symposium on Electrical Insulating Materials, Tokio, Japan, pp. $763-$ 766. 
J.-M. Ramirez-Cortes received the BSc degree from the National Polytechnic Institute, Mexico, the MSc degree from the National Institute of Astrophysics, Optics, and Electronics, Mexico, and the $\mathrm{PhD}$ degree from Texas Tech University, all in electrical engineering. He is currently a titular researcher at the Electronics Department, INAOE, Mexico. His research interests include signal and image processing, biometry, neural networks, fuzzy logic, and pattern recognition.

P. Gomez-Gil received the BSc degree from Universidad de las Americas Puebla, Mexico, the MSc and PhD degrees from Texas Tech University, USA, all in computer science. She is currently an associate researcher in computer science at the National Institute of Astrophysics, Optics, and Electronics, Mexico. Her research interests include neural networks, signal processing, pattern recognition, and software engineering.

V. Alarcon-Aquino received the BSc degree from Instituto Tecnologico de Veracruz, the MSc degree from the National Institute of Astrophysics, Optics, and Electronics, Mexico, and the PhD and DIC degrees from Imperial College London, University of London, London, UK, all in electrical engineering. He is currently a titular professor in the Department of Electronic Engineering at the Universidad de las Américas, Puebla, Mexico. His research interests include network protocols, time-series prediction, wavelet-based digital signal processing, hardware description languages, and multi-resolution neural networks.

D. Baez-Lopez received the BSc degree in physics with honors from Universidad Autonoma de Puebla, Mexico, and MSc and PhD degrees in electrical engineering from University of Arizona, Tucson. He is currently a faculty member at the Electronic Engineering Department of the Universidad de las Americas, Puebla, Mexico. His interests are in the areas of education on circuits and systems, active filters, digital image processing, and biometry.

R. Enriquez-Caldera received the BSc degree from Universidad Nacional Autónoma de México, the MSc degree in physics and applied mathematics, and the PhD degree in electrical engineering, both from University of New Brunswick, Canada. He is currently a titular professor at the Electronics Department, INAOE, Mexico. His research interests include signal processing, instrumentation, and digital communications. 


\section{Rankos atvaizdų morfologinių požymių išskyrimo biometrinė sistema, naudojanti neuroninius tinklus ir atraminiu vektoriu mašinas}

Juan-Manuel RAMIREZ-CORTES, Pilar GOMEZ-GIL, Vicente ALARCON-AQUINO, David BAEZ-LOPEZ, Rogerio ENRIQUEZ-CALDERA

Straipsnyje pateikiama rankos atvaizdu biometrinė sistema, pasižyminti originalia požymiu išskyrimo metodologija, pritaikant morfologinius vaizdu spektrus. Atlikti eksperimentai taikant neuroninius tinklus ir atraminių vektorių mašinu metodus leido pasiekti vidutiniškai $98.5 \%$ tikslumą. Verifikavimo uždavinys buvo sprendžiamas taikant Euklido metrikos klasifikatorių, ivertinant atpažinimo dažni ir atmetimo dažni, panaudojant kryžminio perskirstymo procedūra. Nustatytas vidutiniškas $2.85 \%$ klaidu lygis. Spektru posūkio ir postūmio invariantiškumo savybẻ leidžia sistemai išvengti fiksuotos rankos pozicijos naudojant žymes, kaip ir kitu sistemu atveju. Rezultatai rodo, kad vaizdo spektro analizè galibūti taikoma požymiu išskyrimui biometriniuose pritaikymuose. 